\title{
Neurological diseases as mortality predictive factors for patients with COVID-19: a retrospective cohort study
}

\author{
Jong-moon Hwang ${ }^{1,2} \cdot$ Ju-Hyun Kim ${ }^{1} \cdot$ Jin-Sung Park ${ }^{3} \cdot$ Min Cheol Chang ${ }^{4,5} \cdot$ Donghwi Park $^{6}$ (D)
}

Received: 30 April 2020 / Accepted: 21 June 2020 / Published online: 8 July 2020

(C) Fondazione Società Italiana di Neurologia 2020

\begin{abstract}
Introduction In the current study, we evaluated factors that increase the coronavirus disease (COVID-19) patient death rate by analyzing the data from two cohort hospitals. In addition, we studied whether underlying neurological diseases are risk factors for death.

Methods In this retrospective cohort study, we included 103 adult inpatients (aged $\geq 18$ years). We evaluated differences in demographic data between surviving and non-surviving COVID-19 patients.

Results In a multivariate logistic analysis, age and the presence of chronic lung disease and Alzheimer's dementia (AD) were the only significant parameters for predicting COVID-19 non-survival $(p<0.05)$. However, hypertension, coronary vascular disease, dyslipidemia, chronic kidney disease, diabetes, and history of taking angiotensin II receptor blockers (ARBs) or angiotensinconverting enzyme (ACE) inhibitors, as well as nonsteroidal anti-inflammatory drugs (NSAIDs), were not significantly associated with the death of COVID-19 patients. The optimal cutoff value obtained from the maximum Youden index was 70 (sensitivity, $80.77 \%$; specificity, $61.04 \%$ ), and the odds ratio of non-survival increased 1.055 fold for every year of age.

Conclusions Clinicians should closely monitor and manage the symptoms of COVID-19 patients who are over the age of 70 years or have chronic lung disease or AD.
\end{abstract}

Keywords COVID-19 · Alzheimer's dementia $\cdot$ Chronic lung disease $\cdot$ Coronavirus

\section{Introduction}

In December 2019, an outbreak of a coronavirus disease 2019 (COVID-19) occurred in Wuhan, China, and the disease subsequently spread to approximately 200 countries within approximately 3 months. On March 11, 2020, the World Health Organization (WHO) declared the outbreak a pandemic [1-3]. Approximately 2-5\% of COVID-19 cases result in death from

Jong-moon Hwang and Ju-Hyun Kim contributed equally to this work.

Min Cheol Chang

wheel633@ynu.ac.kr

$\triangle$ Donghwi Park

bdome@hanmail.net

1 Department of Rehabilitation Medicine, Kyungpook National University Hospital, Daegu, South Korea

2 Department of Rehabilitation Medicine, School of Medicine, Kyungpook National University, Daegu, South Korea massive alveolar damage and progressive respiratory failure $[4,5]$. Although the death rate is lower than that of the coronaviruses causing severe acute respiratory syndrome (SARS) and Middle East respiratory syndrome, the highly contagious nature of the 2019 novel coronavirus (SARSCoV-2) has been a factor in an increasing number of deaths from COVID-19 in almost all countries [6]. Efforts to prevent the spread of infection and reduce mortality are actively

3 Department of Neurology, School of medicine, Kyungpook National University Chilgok hospital, Kyungpook National University, Daegu, Republic of Korea

4 Department of Rehabilitation Medicine, College of Medicine, Yeungnam University, Daegu, Republic of Korea

5 Department of Physical Medicine and Rehabilitation, College of Medicine, Yeungnam University 317-1, Daemyungdong, Namku, Taegu 705-717, Republic of Korea

6 Department of Physical Medicine and Rehabilitation, Ulsan University Hospital, University of Ulsan College of Medicine, 877 Bangeojinsunghwndo-ro, Dong-gu, Ulsan 44033, Republic of Korea 
underway in each affected country. Knowledge of the risk factors for COVID-19 patient mortality is essential because it will help government leaders develop more efficient strategies for confronting the COVID-19 outbreak, and help clinicians prioritize care for patients with higher mortality risk. Although a few previous studies have investigated risk factors for mortality, most are limited because they do not consider a range of potential factors [7-9]. Furthermore, due to the limited number of previous studies, risk factors for mortality have not been definitively examined.

After the outbreak in China, the number of COVID-19 cases in South Korea immediately increased due to South Korea's close geographic location to China and the number of people who travel between the two countries. In the current study, we evaluated risk factors for death in COVID-19 patients by considering several possible factors using data from two hospitals in Daegu, South Korea. Furthermore, we studied whether underlying neurological diseases are risk factors for death.

\section{Methods}

\section{Study design and participants}

This retrospective cohort study included two cohorts of adult inpatients ( $\geq 18$ years old) from Kyungpook National University Hospital and Kyungpook National University Chilgok Hospital in Daegu, South Korea. In our study, all adult patients who were diagnosed with COVID-19 according to the WHO interim guidance were screened. Those who were discharged or died between February 1, 2020 (i.e., when the first patients were admitted), and March 25, 2020, were included in the study.

These two hospitals are the largest among the four designated explicitly for patients in the COVID-19 severe stage transferred from other hospitals in Daegu. Therefore, our study enrolled adult inpatients that were hospitalized for the near severe stage of COVID-19 and had an outcome of either discharged or dead in the early stages of the outbreak. As of March 26, 2020, 27.7\% of COVID-19 deaths in Daegu and $20.0 \%$ of COVID-19 deaths in South Korea were included in this study. This study was approved by the Institutional Review Board of Kyungpook National University Hospital, and the requirement for informed consent was waived by the Ethics Commission as described previously.

\section{Data collection}

Clinical, demographic, epidemiological, treatment, medication, and outcome data were extracted from electronic medical records. All data were independently investigated by two physicians ( $\mathrm{JH}$ and $\mathrm{JK}$ ) using standardized data collection forms. Discrepancies were resolved through discussion with a third investigator (DP), and by referring to the original articles. Neurological diseases such as stroke, Parkinson's disease, and Alzheimer's dementia (AD) were reconfirmed by a neurologist (JP).

\section{Laboratory procedures}

Before January 31, 2020, pancoronavirus RT-PCR was used to identify coronavirus in Korea. This test requires two separate assays over a 24-h testing period [10]. After January 31, 2020, each local government's Public Health and Environmental Research Institute began diagnosing COVID-19 using the RT-PCR kit approved by the Korean Centers for Disease Control and Prevention (KCDC) and the Korean Ministry of Food and Drug Safety [11]. Since February 7, 2020, more than 50 private medical institutions in South Korea, which were approved by the KCDC, began to test for SARS-CoV-2 using the RT-PCR kit. Both nasopharyngeal and oropharyngeal swabs were used to diagnose COVID-19 [11].

\section{Risk factors}

The patient's underlying chronic medical and neurological diseases were investigated based on national health insurance system of South Korea diagnosis codes. All underlying neurological diseases such as stroke, idiopathic Parkinson's disease (IPD), and $\mathrm{AD}$ were reconfirmed by a neurologist.

Based on previous studies of COVID-19 risk factors and the classification system announced by the KCDC, the presence of chronic medical underlying diseases such as diabetes, chronic kidney disease (CKD), chronic lung, or cardiovascular disease, carcinoma, dyslipidemia, and hypertension were investigated (Fig. 1). Chronic lung disease was defined as chronic obstructive pulmonary disease, asthma, interstitial lung disease, idiopathic pulmonary fibrosis, or bronchiectasis. Additionally, we investigated the presence of neurological disorders including stroke, IPD, and AD in COVID-19 patients. Patients with a medication history involving ARBs or ACE inhibitors and NSAIDs, such as ibuprofen, were also included in the study. It is important to note that NSAIDs have recently been suspected to be related to COVID-19 through the angiotensin-converting enzyme 2 (ACE2).

\section{Statistical analysis}

To identify differences in demographic data between COVID19 survivors and non-survivors, two sample $t$ tests, MannWhitney $U$ tests, or Chi-squared tests were performed, as 


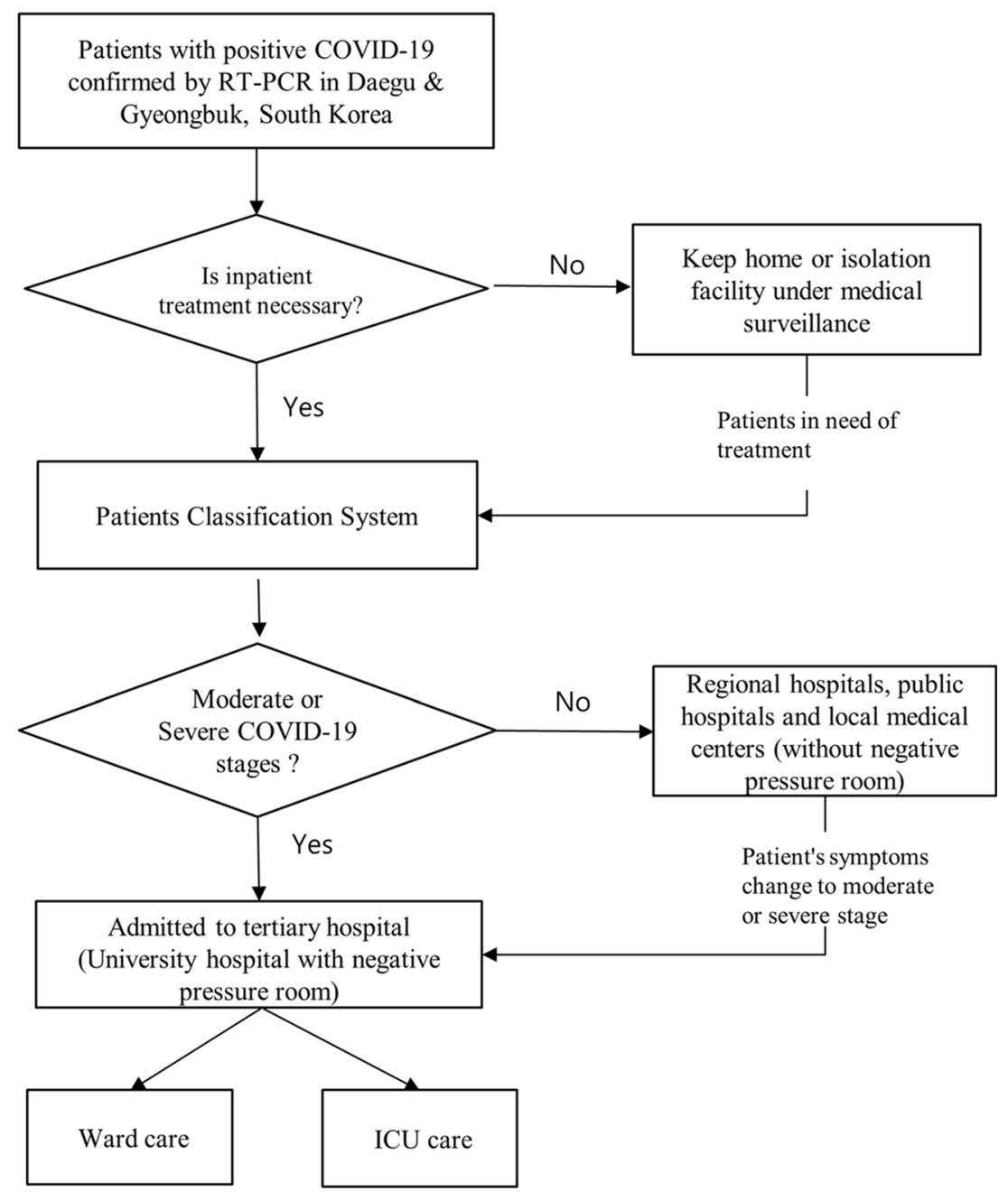

Fig. 1 Classification of patients with coronavirus disease 2019 (COVID19) and protective methods according to classification. There are four classification stages in South Korea: asymptomatic, mild, moderate, and severe. The asymptomatic stage meets all of the following conditions: (1) fully conscious, $(2)<50$ years old, (3) no underlying disease, (4) nonsmoker, and $(5)<37.5{ }^{\circ} \mathrm{C}$ temperature without antipyretics. The mild stage is full consciousness with one or more of the following conditions: (1) $\geq 50$ years old, $(2) \geq 1$ underlying disease, and $(3) \leq 38^{\circ} \mathrm{C}$ temperature

appropriate. In addition, to analyze the correlation between the clinical parameters of underlying diseases and survival rates in COVID-19 patients, the Cox proportional hazards regression model was used, and the values of the beta coefficient, standard error, hazard ratio, confidence interval of hazard ratio, and $p$ were used for multivariate analysis. To evaluate the predictive factor accuracy of age for mortality in patients with COVID-19, we performed a receiver operating characteristic (ROC) analysis. Survival analysis was performed using Kaplan-Meier method, and differences in patient survival periods were determined by employing the log-rank test with respect to the presence of AD. All statistical analyses were conducted using SPSS version 22.0 (IBM, Armonk, NY, USA). after taking antipyretics. The moderate stage is full consciousness and one or more of the following conditions: $(1)>38{ }^{\circ} \mathrm{C}$ temperature even after taking antipyretics and (2) respiratory difficulty. The severe stage is when the patient is unconscious. Underlying diseases: diabetes, chronic kidney disease, chronic liver disease, chronic lung disease, chronic cardiovascular disease, blood cancer, cancer patients undergoing chemotherapy, patients taking immunosuppressant drugs, and human immunodeficiency virus disease

\section{Results}

\section{Patient demographics}

A total of 103 adult patients who were hospitalized at Kyungpook National University Hospital and Kyungpook National University Chilgok Hospital for COVID-19 before March 26, 2020, were enrolled in the final analysis of this study. Twenty-six patients died during hospitalization, and 77 were discharged. Mean patient age was $67.62 \pm$ 15.32 years, with ages ranging from 24 to 97 years, and the sex ratio (male:female) was 52:51 (Table 1). Comorbidities were present in $72.6 \%$ of the patients. Hypertension was the 
Table 1 Clinical characteristics of patients with COVID-19

\begin{tabular}{|c|c|c|c|c|}
\hline Variable & Total & Survivor & $\begin{array}{l}\text { Non- } \\
\text { survivor }\end{array}$ & $p$ value \\
\hline Total, $n(\%)$ & $103(100 \%)$ & $77(75 \%)$ & $26(25 \%)$ & \\
\hline Age, years & $67.62 \pm 15.32$ & $64.62 \pm 15.84$ & $76.50 \pm 9.25$ & $.000 *$ \\
\hline \multicolumn{5}{|l|}{ Gender, $n(\%)$} \\
\hline $\begin{array}{l}\text { Female } \\
\text { Male }\end{array}$ & $\begin{array}{l}51(50 \%) \\
52(50 \%)\end{array}$ & $\begin{array}{l}41(53 \%) \\
36(47 \%)\end{array}$ & $\begin{array}{l}10(38 \%) \\
16(62 \%)\end{array}$ & .192 \\
\hline \multicolumn{5}{|l|}{ Comorbidities } \\
\hline Hypertension & $57(55 \%)$ & $40(52 \%)$ & $17(65 \%)$ & .233 \\
\hline Diabetes mellitus & $35(34 \%)$ & $21(27 \%)$ & $14(54 \%)$ & $.013 *$ \\
\hline Chronic kidney disease & $17(17 \%)$ & $14(18 \%)$ & $3(12 \%)$ & .430 \\
\hline Dyslipidemia & $13(13 \%)$ & $10(13 \%)$ & $3(12 \%)$ & .848 \\
\hline Chronic lung disease & $7(7 \%)$ & $2(3 \%)$ & $5(19 \%)$ & $.004 *$ \\
\hline Carcinoma & $9(9 \%)$ & $5(6 \%)$ & $4(15 \%)$ & .165 \\
\hline Cardiovascular disease & $12(12 \%)$ & $6(8 \%)$ & $6(23 \%)$ & $.036^{*}$ \\
\hline Dementia & $11(11 \%)$ & $3(4 \%)$ & $8(31 \%)$ & $.000 *$ \\
\hline Parkinson disease & $2(2 \%)$ & $1(1 \%)$ & $1(4 \%)$ & .416 \\
\hline Stroke & $4(4 \%)$ & $1(1 \%)$ & $3(12 \%)$ & $.019 *$ \\
\hline Taking NSAIDs & $5(5 \%)$ & $3(4 \%)$ & $2(8 \%)$ & .436 \\
\hline Taking ARB or ACEi & $13(13 \%)$ & $8(10 \%)$ & $5(19 \%)$ & .338 \\
\hline \multicolumn{5}{|l|}{ Hospitalization type } \\
\hline $\begin{array}{l}\text { Ward } \\
\text { ICU }\end{array}$ & $\begin{array}{l}77(75 \%) \\
26(25 \%)\end{array}$ & $\begin{array}{l}57(74 \%) \\
20(26 \%)\end{array}$ & $\begin{array}{l}20(77 \%) \\
6(23 \%)\end{array}$ & .769 \\
\hline \multicolumn{5}{|l|}{ Types of intensive care } \\
\hline Mechanical ventilator & $27(26 \%)$ & $22(29 \%)$ & $5(19 \%)$ & .349 \\
\hline ECMO & $4(4 \%)$ & $2(3 \%)$ & $2(8 \%)$ & .245 \\
\hline
\end{tabular}

$p$ values were calculated by independent $T$ test or Chi-square test as appropriate

ECMO extracorporeal membrane oxygenation, ICU intensive care unit, COVID-19 coronavirus disease 2019, $A R B$ angiotensin receptor blocker, $A C E i$ angiotensin-converting enzyme inhibitor, NSAIDs non-steroidal antiinflammatory drugs

*Significant difference noted compared between two groups $(p<.05)$. Values: mean \pm standard deviation most common comorbidity affecting $55.3 \%$ of patients, followed by diabetes $(34.0 \%)$ and CKD (16.5\%) (Table 1).

\section{Treatment methods}

Of the 103 patients, four $(3.9 \%)$ were treated with extracorporeal membrane oxygenation (ECMO), 27 (26.2\%) were intubated and placed on a mechanical ventilator, and $26(25.2 \%)$ were treated in the intensive unit care (ICU). All hospitalized patients were treated with either two tablets of lopinavir/ritonavir $200 \mathrm{mg} / 50 \mathrm{mg}$ (Kaletra ${ }^{\circledR}$, AbbVie Inc., North Chicago, IL, USA) alone or a combination of two tablets of lopinavir/ritonavir $200 \mathrm{mg} / 50 \mathrm{mg}$ and hydroxychloroquine sulfate $400 \mathrm{mg}$ (Oxiklorine ${ }^{\circledR}$, Myungmoon Pharm. Co., Ltd., Seoul, South Korea) for anti-viral treatment. With the exception of four surviving patients, all other patients received treatment with the listed oral medications.

\section{Risk factors for non-survival}

Comparing the demographic data between survivor and nonsurvivor COVID-19 patients, there was a significant difference in age $(p<0.05)$ (Table 1). In a comparison of underlying disease comorbidities between survivor and non-survivor COVID-19 patients, the presence of diabetes, chronic lung disease, coronary vascular disease, $\mathrm{AD}$, and stroke was significantly higher in the non-survivor group compared with the survivor group $(p<0.05)$ (Table 1). However, the presence of hypertension, CKD, IPD, or dyslipidemia was not significantly different between the non-survivor and survivor groups. However, patients with a history of taking ARBs or ACE inhibitors, as well as NSAIDs, showed no statistically significant differences in death rate.

In a multivariate logistic analysis, age and the presence of chronic lung disease and AD were the only significant parameters for predicting COVID-19 non-survivors $(p<0.05)$ (Table 2). In COVID-19 patients, the area under the ROC 
Table 2 Risk factors associated with mortality in patients with COVID-19 using multivariate logistic analysis

\begin{tabular}{lcccc}
\hline Parameter & Beta coefficient & Standard error & HR $(95 \%$ CI $)$ & $p$ value \\
\hline Age & .053 & .026 & $1.055(1.003-1.109)$ & $.039^{*}$ \\
Diabetes mellitus & 1.090 & .587 & $2.974(0.942-9.390)$ & .063 \\
Chronic lung disease & 2.615 & .961 & $13.665(2.077-89.915)$ & $.007^{*}$ \\
Cardiovascular disease & .939 & .798 & $2.556(0.535-12.207)$ & .239 \\
Alzheimer's dementia & 2.041 & .836 & $7.698(1.496-39.610)$ & $.015^{*}$ \\
Stroke & -1.276 & 1.325 & $0.279(0.021-3.747)$ & .335 \\
\hline $\begin{array}{l}\text { H values by cox proportional hazard model } \\
\text { * Statistical significant with } p<.05\end{array}$ & & &
\end{tabular}

curve on age for predicting non-survival was $0.742(95 \% \mathrm{CI}$, $0.646-0.823 ; p<0.0001$ ) (Table 3 ). The optimal cutoff value obtained from the maximum Youden Index (J) was 70 (sensitivity, $80.77 \%$; specificity, $61.04 \%$ ), and the odds ratio of nonsurvival increased 1.055 fold for every year of age (Fig. 2).

\section{$A D$ as a risk factor for mortality}

Of the 11 AD patients with COVID-19, eight (72.72\%) died. The AD patients with COVID-19 who were included in this study are shown in Table 3. The average age of AD patients with COVID-19 was $80.27 \pm 10.10$ years, with ages ranging from 58 to 97 years, and the sex ratio (male:female) was 6:5. The survival rate of $31 \%$ was lower among COVID-19 patients with $\mathrm{AD}$ compared to $5 \%$ for COVID-19 patients without $\mathrm{AD}$. The difference in survival rates according to the presence of AD was statistically significant $(p<0.0001)$ (Fig. 3).

\section{Discussion}

In the current study, we evaluated risk factors for mortality in patients with COVID-19 by analyzing the data from two major hospitals in Daegu, in which only patients with severe symptoms were admitted. Our study included approximately

Table 3 ROC curve analysis of age for mortality of COVID-19

\begin{tabular}{lcccc}
\hline Parameter & AUC & Standard error & $p$ value & $95 \% \mathrm{CI}$ \\
\hline Age & .742 & .052 & $.000^{*}$ & $0.640-0.844$ \\
\hline
\end{tabular}

$A U C$ area under the ROC curve, $C I$ confidence interval

* Significant difference noted $(p<.05)$
$20 \%$ of the total COVID-19 death cases in South Korea. Of the 103 included patients, 26 (25.2\%) died despite active treatment with anti-viral medication, ECMO, and mechanical ventilation. We found that the presence of chronic lung disease and $\mathrm{AD}$ were predictive factors for death from COVID-19, especially mortality risk increases beginning at the age of 70 years.

Our findings showing that older age is one of the risk factors for mortality in patients with COVID-19 correspond with

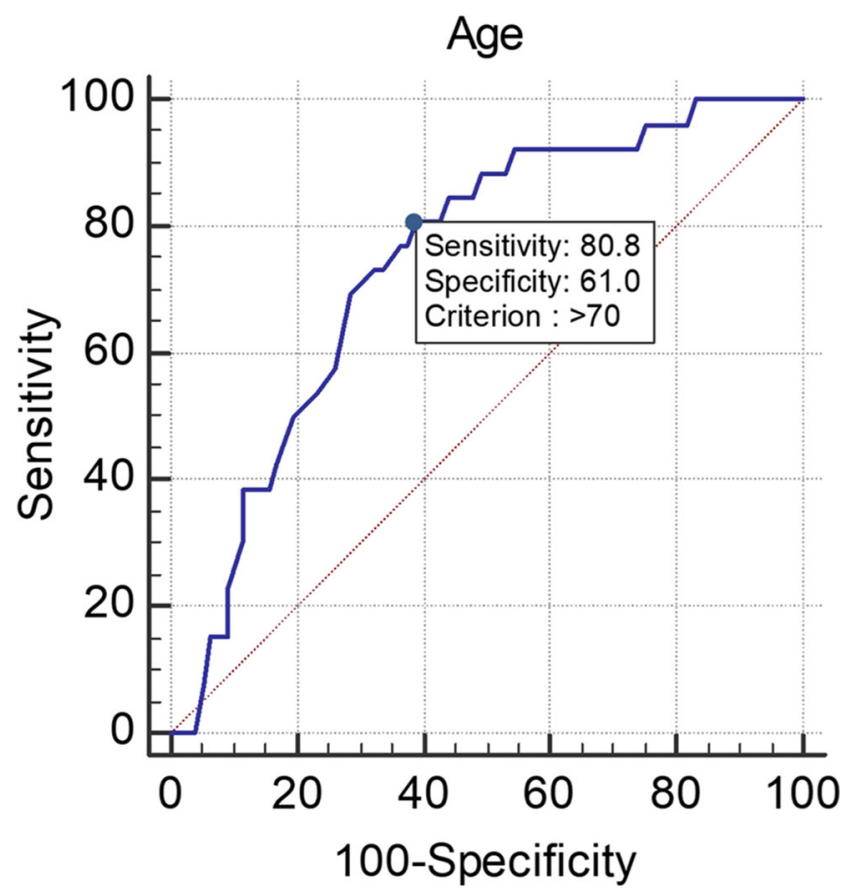

Fig. 2 The area under the ROC curve for age predicting non-survival was 0.742 (95\% CI, $0.640-0.844 ; p<0.0001$ ). The optimal cutoff value obtained from the maximum Youden Index (J) was 70 (sensitivity, 80.8\%; specificity, $61.0 \%$ ), and the odds ratio for non-survival increased 1.055 fold for every year of age 
Survival Functions

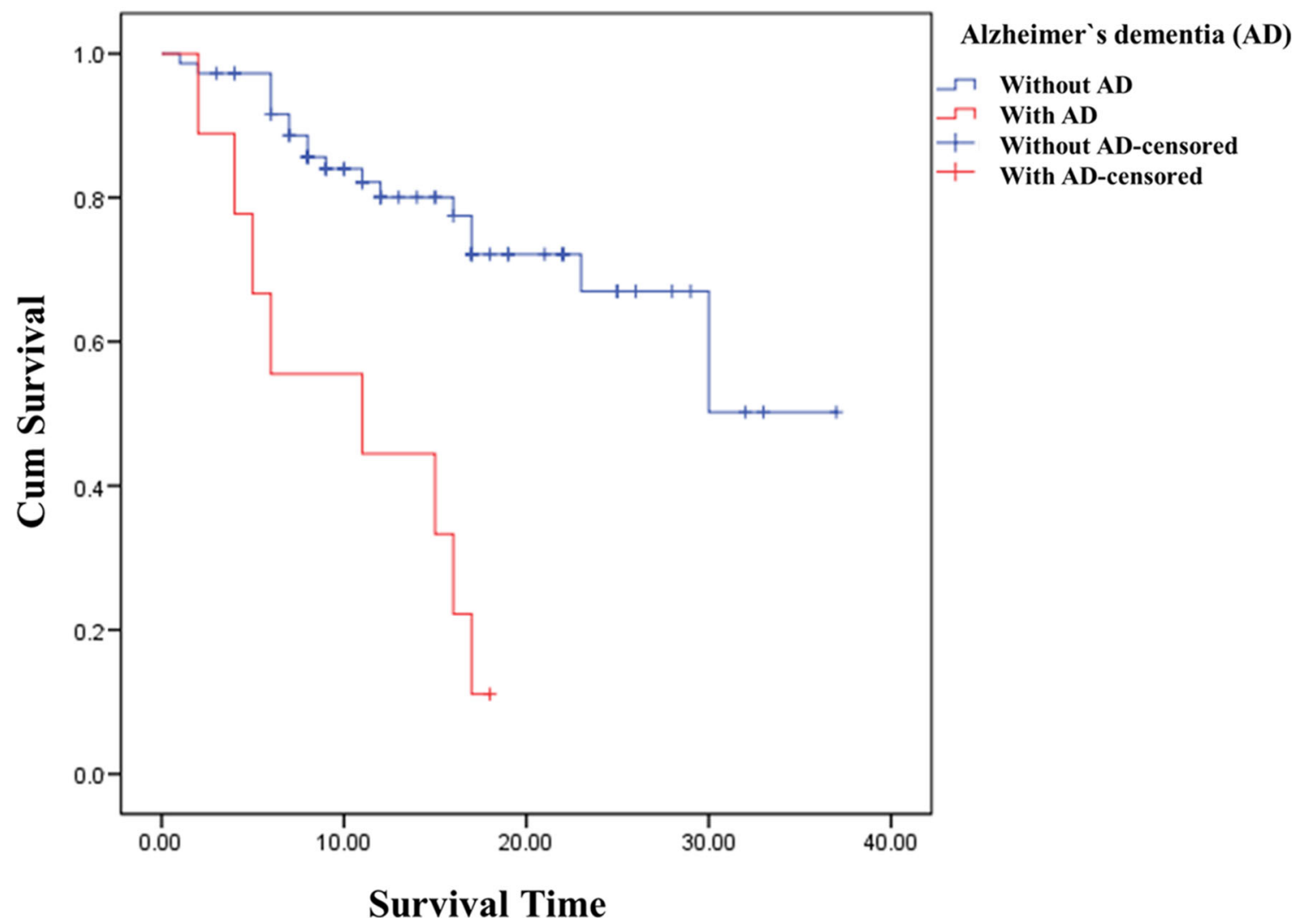

Fig. 3 Cumulative survival of patients with COVID-19 based on the presence of Alzheimer's dementia (AD). The difference in survival rates according to the presence of $\mathrm{AD}$ was statistically significant $(p<0.0001)$

previous studies [7, 9]. The study by Zhou et al. [9] included 191 patients. Of these patients, 54 died, and it was reported that increased age was associated with death in COVID-19 patients. In addition, Porcheddu et al. [7] reported, in the early stages of the outbreak in northern Italy, that death mainly occurred in older patients. It was proposed that agedependent functional defects in immunologic cells, such as $\mathrm{T}$ cells and $\mathrm{B}$ cells, and the excess production of various cytokines could result in impaired control of viral replication $[12,13]$. Prolonged proinflammatory responses in older adults may also be responsible for the high death rate in patients in this age group [14].

Regarding underlying diseases, we found that chronic lung disease and $\mathrm{AD}$ increase the mortality rate in COVID-19 patients. In previous studies, several diseases, including diabetes, hypertension, coronary artery disease, cerebrovascular diseases, chronic renal disease, and chronic lung disease, are reported to be risk factors for death from COVID-19 [15-17]. This discrepancy might be due to the relatively small sample size in our study. However, our finding that $\mathrm{AD}$ is risk factor of death from COVID-19 has not been previously reported. Alterations in the peripheral immune response are known to play a role in $\mathrm{AD}$ pathology [18-20]. Busse et al. [21] reported that, compared to an age-matched healthy control group, 60 patients with $\mathrm{AD}$ had decreased numbers of $B$ cells and $\mathrm{T}$ cells. The number of regulatory $\mathrm{T}$ cells (e.g., CD4+ and CD8+ T cells), which plays a critical role in maintaining peripheral tolerance and controlling acute, persistent infections, was notably altered in $\mathrm{AD}$, but not in other types of dementia, such as vascular or frontotemporal dementia [21]. Therefore, unlike stroke associated with vascular dementia, it is thought that the significant increase in mortality in $\mathrm{AD}$ patients with COVID-19 might be due to these alterations in the peripheral immune response.

SARS-CoV-2 binds to ACE2 in the human body [22]. ACE2 is known to be expressed broadly in the lungs, heart, blood vessels, brain, and intestines [23]. Of these target organs, the lungs are the most vulnerable to SARS-CoV-2 infection. There have been concerns that ACE inhibitors and ARBs might increase ACE2 expression and increase patients' susceptibility to SARS-CoV-2 [24]. Furthermore, it has been proposed that NSAID use might weaken inflammatory effects that suppress SARS-CoV-2 survival [25]. However, our study showed that the use of those medications is not associated with changes in COVID-19 death rates.

In our study, we found that older patients, especially those over the age of 70 years, are likely to die from COVID-19. In 
addition, the presence of chronic lung disease and $\mathrm{AD}$ predicted a higher risk of death. Therefore, we recommend close observation and active symptom treatment when patients with COVID-19 have the previously mentioned risk factors (old age, chronic lung disease, and $\mathrm{AD}$ ). In addition, the government should pay special attention to, and continue developing new measures for, preventing SARS-CoV-2 infection in patients with risk factors for mortality. To the best of our knowledge, this is the first study to show that AD increases the death rate of COVID-19 patients. However, our study is limited in that it was conducted retrospectively using a small number of COVID-19 cases. Further studies are therefore necessary to address these limitations.

Author contributions J.H: Curation of data. J.K: Curation of data. M.C: Writing and editing article. D.P: Writing article, concept of study design, critical editing the manuscript.

Funding Information The present study was supported by a National Research Foundation of Korea grant funded by the Korean government (grant no. NRF-2019M3E5D1A02068106).

\section{Compliance with ethical standards}

Conflict of interest No commercial party having a direct financial interest in the results of the research supporting this article has or will confer a benefit upon the authors or upon any organization with which the authors are associated.

Ethical approval All procedures performed in studies involving human participants were in accordance with the ethical standards of the institutional and/or national research committee and with the 1964 Helsinki declaration and its later amendments or comparable ethical standards.

\section{References}

1. Chang MC, Park D (2020) How should rehabilitative departments of hospitals prepare for coronavirus disease 2019? Am J Phys Med Rehabil 99:475-476. https://doi.org/10.1097/PHM. 0000000000001428

2. Chang MC, Seo WS, Park D, Hur J (2020) Analysis of SARS-CoV2 screening clinic (including drive-through system) data at a single University Hospital in South Korea from 27 January 2020 to 31 March 2020 during the COVID-19 outbreak. Healthcare 8:E145. https://doi.org/10.3390/healthcare8020145

3. Chang MC, Park D (2020) How can Blockchain help people in the event of pandemics such as the COVID-19? J Med Syst 44:102. https://doi.org/10.1007/s10916-020-01577-8

4. Kucharski AJ, Russell TW, Diamond C, Liu Y, Edmunds J, Funk S, Eggo RM, Sun F, Jit M, Munday JD, Davies N, Gimma A, van Zandvoort K, Gibbs H, Hellewell J, Jarvis CI, Clifford S, Quilty BJ, Bosse NI, Abbott S, Klepac P, Flasche S (2020) Early dynamics of transmission and control of COVID-19: a mathematical modelling study. Lancet Infect Dis 20:553-558. https://doi.org/10.1016/ S1473-3099(20)30144-4

5. Cascella M, Rajnik M, Cuomo A, Dulebohn SC, Di Napoli R (2020) Features, evaluation and treatment coronavirus (COVID19). StatPearls, Treasure Island (FL)
6. Guo YR, Cao QD, Hong ZS, Tan YY, Chen SD, Jin HJ, Tan KS, Wang DY, Yan Y (2020) The origin, transmission and clinical therapies on coronavirus disease 2019 (COVID-19) outbreak - an update on the status. Mil Med Res 7:11. https://doi.org/10.1186/ s40779-020-00240-0

7. Porcheddu R, Serra C, Kelvin D, Kelvin N, Rubino S (2020) Similarity in case fatality rates (CFR) of COVID-19/SARS-COV2 in Italy and China. J Infect Dev Ctries 14:125-128. https://doi. org $/ 10.3855 /$ jidc. 12600

8. Shi S, Qin M, Shen B, Cai Y, Liu T, Yang F, Gong W, Liu X, Liang J, Zhao Q, Huang H, Yang B, Huang C (2020) Association of cardiac injury with mortality in hospitalized patients with COVID-19 in Wuhan, China. JAMA Cardiol 25:e200950. https:// doi.org/10.1001/jamacardio.2020.0950

9. Zhou F, Yu T, Du R, Fan G, Liu Y, Liu Z et al (2020) Clinical course and risk factors for mortality of adult inpatients with COVID-19 in Wuhan, China: a retrospective cohort study. Lancet 395:1054-1062. https://doi.org/10.1016/S0140-6736(20)30566-3

10. Chang MC, Hur J, Park D (2020) Interpreting the COVID-19 test results: a guide for physiatrists. Am J Phys med Rehabil [online ahead of print]. https://doi.org/10.1097/PHM.0000000000001471

11. Kim JY (2020) Letter to the editor: case of the index patient who caused tertiary transmission of coronavirus disease 2019 in Korea: the application of Lopinavir/ritonavir for the treatment of COVID19 pneumonia monitored by quantitative RT-PCR. J Korean Med Sci 35:e88. https://doi.org/10.3346/jkms.2020.35.e88

12. Bektas A, Schurman SH, Sen R, Ferrucci L (2017) Human T cell immunosenescence and inflammation in aging. J Leukoc Biol 102: 977-988. https://doi.org/10.1189/jlb.3RI0716-335R

13. Salam N, Rane S, Das R, Faulkner M, Gund R, Kandpal U, Lewis V, Mattoo H, Prabhu S, Ranganathan V, Durdik J, George A, Rath S, Bal V (2013) T cell ageing: effects of age on development, survival \& function. Indian J Med Res 138:595-608

14. Chung HY, Kim DH, Lee EK, Chung KW, Chung S, Lee B et al (2019) Redefining chronic inflammation in aging and age-related diseases: proposal of the senoinflammation concept. Aging Dis 10: 367-382. https://doi.org/10.14336/AD.2018.0324

15. Guan WJ, Ni ZY, Hu Y, Liang WH, Ou CQ, He JX, Liu L, Shan H, Lei CL, Hui DSC, du B, Li LJ, Zeng G, Yuen KY, Chen RC, Tang CL, Wang T, Chen PY, Xiang J, Li SY, Wang JL, Liang ZJ, Peng YX, Wei L, Liu Y, Hu YH, Peng P, Wang JM, Liu JY, Chen Z, Li G, Zheng ZJ, Qiu SQ, Luo J, Ye CJ, Zhu SY, Zhong NS, China Medical Treatment Expert Group for Covid-19 (2020) Clinical characteristics of coronavirus disease 2019 in China. N Engl J Med 382:1708-1720. https://doi.org/10.1056/NEJMoa2002032

16. Lippi G, Mattiuzzi C, Sanchis-Gomar F, Henry BM (2020) Clinical and demographic characteristics of patients dying from COVID-19 in Italy versus China. J Med Virol [online ahead of print]. https:// doi.org/10.1002/jmv. 25860

17. Team CC-R (2020) Preliminary estimates of the prevalence of selected underlying health conditions among patients with coronavirus disease 2019 - United States, February 12-March 28, 2020. MMWR Morb Mortal Wkly Rep 69:382-386. https://doi.org/10. 15585/mmwr.mm6913e2

18. Town T, Tan J, Flavell RA, Mullan M (2005) T-cells in Alzheimer's disease. NeuroMolecular Med 7:255-264. https:// doi.org/10.1385/NMM:7:3:255

19. Baruch K, Rosenzweig N, Kertser A, Deczkowska A, Sharif AM, Spinrad A, Tsitsou-Kampeli A, Sarel A, Cahalon L, Schwartz M (2015) Breaking immune tolerance by targeting Foxp3(+) regulatory T cells mitigates Alzheimer's disease pathology. Nat Commun 6:7967. https://doi.org/10.1038/ncomms8967

20. McManus RM, Heneka MT (2020) T cells in Alzheimer's disease: space invaders. Lancet Neurol 19:285-287. https://doi.org/10. 1016/S1474-4422(20)30076-4 
21. Busse M, Michler E, von Hoff F, Dobrowolny H, Hartig R, Frodl T, Busse S (2017) Alterations in the peripheral immune system in dementia. J Alzheimers Dis 58:1303-1313. https://doi.org/10. 3233/JAD-161304

22. Wan Y, Shang J, Graham R, Baric RS, Li F (2020) Receptor recognition by the novel coronavirus from Wuhan: an analysis based on decade-long structural studies of SARS coronavirus. J Virol 94: e00127-e00120. https://doi.org/10.1128/JVI.00127-20

23. Hamming I, Timens W, Bulthuis ML, Lely AT, Navis G, van Goor H (2004) Tissue distribution of ACE2 protein, the functional receptor for SARS coronavirus. A first step in understanding SARS pathogenesis. J Pathol 203:631-637. https://doi.org/10.1002/path.1570
24. Patel AB, Verma A (2020) COVID-19 and angiotensin-converting enzyme inhibitors and angiotensin receptor blockers: what is the evidence? JAMA [Online ahead of print]. https://doi.org/10.1001/ jama.2020.4812

25. Day M (2020) Covid-19: European drugs agency to review safety of ibuprofen. BMJ 368:m1 168. https://doi.org/10.1136/bmj.m1168

Publisher's note Springer Nature remains neutral with regard to jurisdictional claims in published maps and institutional affiliations. 